\title{
COMPARAÇÃO DE PROTOCOLOS EM ENSAIOS DE PREFERÊNCIA ALIMENTAR EM CÃES
}

\author{
(Comparison of protocols in preference tests in dogs) \\ Carolina Pedro Zanatta ${ }^{1}$, Diego Surek ${ }^{2}$, Larissa Wünsche Risolia ${ }^{1}$, Tabyta Tamara Sabchuk ${ }^{1}$, \\ Ananda Portella Félix ${ }^{1}$, Alex Maiorka ${ }^{1}$, Simone Gisele Oliveira ${ }^{1}$ \\ ${ }^{1}$ Setor de Ciências Agrárias. Universidade Federal do Paraná, ²Empresa Brasileira de Pesquisa Agropecuária. \\ *Correspondência: sgoliveira@ufpr.br
}

RESUMO: Com o objetivo de determinar o protocolo mais adequado para realização de ensaios de preferência alimentar, considerando como fonte de variação número de animais e dias de avaliação, foi realizado o presente experimento, avaliando razão de ingestão (RI) e primeira escolha em cães. Os tratamentos foram: Protocolo 1: 32 cães avaliados por um dia (P32); Protocolo 2: 16 cães avaliados por dois dias (P16); Protocolo 3: 8 cães avaliados por quatro dias (P8). Os protocolos foram planejados de forma a fornecer ao final do período de avaliação um total de 32 observações por tratamento, sendo cada protocolo repetido por quatro períodos de avaliação. $A$ RI do alimento $A(R I A)$ foi calculada segundo a equação: RIA $(\%)=[\text { Consumo } A /(\text { Consumo } A+\text { Consumo } B)]^{*} 100$. Os dados foram submetidos à análise de variância e as médias comparadas pelo teste de Tukey $(P<0,05)$. Para análise dos dados para primeira escolha, as observações foram agrupadas em relação à dieta $A$ por protocolo, totalizando em 32 observações por protocolo, e comparadas pelo teste de Qui-quadrado. O P32 apresentou a RIA mais próxima de $50 \%(\mathrm{RIA}=51,77 \%)$, o que indica que 0 consumo de ambas a dietas foi próximo, não havendo preferência por alguma delas. Diferentemente do P16 (RIA $=54,97 \%$ ), que apresentou preferência pela dieta A. O P8 foi igual aos demais protocolos $(\mathrm{RIA}=54,00 \%)$. Para primeira escolha os três protocolos avaliados não diferiram entre si, sendo igualmente capazes de detectar diferença entre as dietas A e B. Conclui-se que, para ensaios de preferência alimentar, o protocolo mais adequado é utilizar 16 cães por dois dias (P16).

Palavras-chave: dias de avaliação; palatabilizante; primeira escolha; razão de ingestão

ABSTRACT: Aiming to determine the most appropriate protocol for testing food preference, considering sources of variation the number of animals and days of trial, the present experiment was conducted, assessing intake ratio (IR) and first approach in dogs. The treatments were: Protocol 1: 32 dogs evaluated by one day (P32); Protocol 2: 16 dogs evaluated for two days (P16);and Protocol 3: 8 dogs evaluated for four days (P8). Protocols were designed in order to provide at the end of the trial period a total of 32 observations per treatment.Each protocol was repeated four times. The diet $\mathrm{A}$ IR (IRA) was calculated according to the equation: IRA $(\%)=\left[\right.$ Consumption A / (Consumption A + Consumption B) ${ }^{*} 100$. Data were submited to analysis of variance and means were compared by Tukey's test ( $P$ $<0.05)$.To the data analysis for first approach, the observations were grouped in 
relation to diet $A$ per protocol, in a total of 32 observations per protocol, and compared by chi-square. The P32 showed the IRA closer to 50\% (IRA = 51.77\%), indicating no differences between $\operatorname{diet} A$ and $B$ intake. Unlike the P16 (IRA = $54.97 \%)$, which showed preference for diet A. The P8 was similar to other protocols $($ IRA $=54.00 \%)$. First approach for the three protocols analyzed did not differ, and they are equal capable to detect differences between diets $A$ and $B$. It is concluded that for food preference trials, the most appropriate protocol is the use of 16 dogs during two days (P16).

Keywords: evaluation days; palatant; first approach; intake ratio

\section{INTRODUÇÃO}

Os ensaios de preferência alimentar são constituídos pela etapa de determinação da primeira escolha, que é a primeira seleção do animal frente a duas dietas ofertadas, e pelo consumo alimentar, definida pela quantidade de cada alimento consumido pelo animal. Em 1984, GRIFFIN et al. relataram a importância de se realizar testes de preferência alimentar pelos cães, previamente ao lançamento de determinado alimento ou produto no mercado. Entretanto, os autores observaram discrepante diferença entre testes realizados com cães alojados em canis experimentais contra cães mantidos em domicílios. Além disso, o modo como os cães de domicilio foram alimentados, aliado ao comportamento do dono com o animal de estimação, podem ter interferido no resultado final. Para realização do teste GRIFFIN et al. (1984) utilizaram diferentes raças, por dois dias, com diferentes idades, pesos e sexos dos cães e também atribuíram a esses fatores uma interferência nos resultados.

A realização de ensaios de preferência alimentar em canis experimentais permite controle de alguns fatores interferentes. Dependendo do número de animais exigidos para determinado teste, é possível padronizá-lo para raça, idade, sexo dos cães a serem utilizados. Além disso, a seleção dos animais para realização de ensaios de preferência alimentar é de grande importância, a fim de evitar viés e erros de análise.

Desse modo, LAROSE (2003) indica o uso de animais saudáveis, que não apresentem sinais de estresse ou desvios de comportamento e que sejam previamente treinados. $\mathrm{O}$ autor recomenda ainda a utilização de diferentes raças e alto número de cães (mínimo de 30 animais) para garantir a confiabilidade dos resultados e permitir análise estatística. Entretanto, não indica quantos dias de avaliação são necessários para se obter um bom resultado. Frente essas colocações, o objetivo desse trabalho foi determinar qual protocolo é mais adequado para realização de ensaios de preferência alimentar em cães, considerando como fonte de variação número de animais e dias de avaliação.

\section{MATERIAL E METODOS}

O experimento foi aprovado pela Comissão de Ética ao Uso de Animais, protocolo n.027/2011, do Setor de Ciências Agrárias da Universidade Federal do Paraná em 14 de outubro de 2011.

Foram utilizados 32 cães adultos, machos e fêmeas, com idade média de 3,5 anos ( \pm 1 ano), das raças: Labrador, Basset Hound, Husky Siberiano, Beagle, Shih Tzu, Maltês, Basenji e Pug. Os 
cães foram procedentes do canil comercial Rancho da Pedra, localizado em Apucarana - PR, vacinados, desverminados e alojados em baias de alvenaria individuais.

As dietas experimentais utilizadas apresentavam mesma composição nutricional (farinha de vísceras de frango, Farinha de Peixe, Farelo de Gérmen de Milho, Metionina, Milho Integral Moído, Ovo em Pó, Polpa de Beterraba, Quirera de Arroz, Semente de Linhaça, Hexametafosfato de Sódio, Extrato Vegetal de Yucca, FrutoOligossacarídeos, MananoOligossacarídeos, Cloreto de Sódio, Complexo vitamínico e mineral), e composição química (Tabela 1), diferindo apenas quanto aos palatabilizantes aplicados (hidrolisado de fígado de aves), ambos na concentração de 3\%.

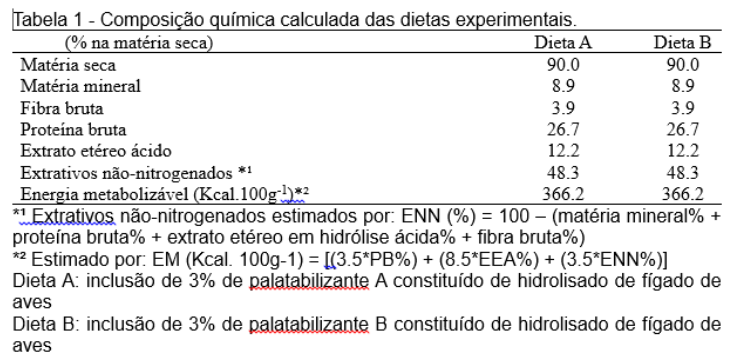

As dietas foram produzidas e posteriormente receberam banho de óleo ( $3 \%$ de óleo de frango), seguido da aplicação dos palatabilizantes na forma líquida, em betoneira com pistola de ar (spray). A quantidade de cada dieta teste foi fornecida para suprir as necessidades de energia metabolizável (NEM) do animal segundo a equação: NEM $(\mathrm{kcal} / \mathrm{dia})=130 \times$ Peso corporal ${ }^{0,75}$, preconizada pelo NATIONAL RESEARCH COUNCIL NRC (2006), acrescida de 30\%, registrando-se 0 peso individual ofertado.

O arraçoamento foi realizado uma vez ao dia, às 18:00 horas, sendo as dietas ofertadas simultaneamente, em comedouros idênticos previamente marcados, alternando-se a posição relativa de cada um a cada refeição, de forma a não condicionar o animal ao local de alimentação.

Os cães tiveram acesso à ração por um período de 30 minutos, não recebendo qualquer outra alimentação no decorrer do dia. Ambos os comedouros foram retirados das baias no caso de animais que consumiram totalmente uma das dietas antes do período de 30 minutos, registrando-se o peso das sobras, para cálculo do consumo de cada dieta e da razão de ingestão (RI).

O ensaio de primeira escolha foi feito pelo método da dupla escolha (adaptado de SOLÀ-ORIOL et al., 2009), o qual consiste no registro do qual dos dois comedouros 0 animal primeiro se aproxima, independente se houve consumo ou não.

Foram comparados três protocolos, diferindo quanto ao número de animais e dias de avaliação, distribuídos da seguinte maneira: Protocolo 1: 32 cães avaliados por um dia (P32); Protocolo 2: 16 cães avaliados por dois dias (P16) e Protocolo 3: 8 cães avaliados por quatro dias (P8). Os protocolos foram planejados de forma a fornecer ao final do período de avaliação um total de 32 observações por tratamento, sendo repetido por quatro períodos no tempo, com intervalo de 15 dias, conforme mostrado na Tabela 2 . A cada repetição no tempo era realizada uma nova batida de ração, a fim de evitar efeito da volatilização dos palatabilizantes entre o primeiro e o último teste. Os quatro protocolos foram compostos por todas as raças.

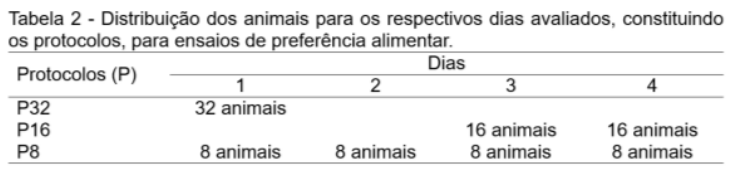


Para análise dos dados de primeira escolha, as observações foram agrupadas em relação à dieta por protocolo, nos quatro tempos avaliados, totalizando em 128 observações por protocolo. Os dados foram comparados pelo teste de Qui-quadrado a $5 \%$ de probabilidade. Esse teste compara a quantidade de frequência observada (FO) contra a frequência esperada (FE) para primeira escolha pela dieta $A$, a fim de averiguar se elas diferem.

Os dados de ingestão foram utilizados para cálculo da Razão de Ingestão $(\mathrm{Rl})$, para os respectivos dias analisados, por meio da seguinte equação:

$\mathrm{RI}$ da dieta $\mathrm{A}(\%)=[$ Consumo da dieta $\mathrm{A} /($ Consumo da $\operatorname{dieta} \mathrm{A}+$ Consumo da dieta B)] ${ }^{\star} 100$

Os dados de RIA foram submetidos ao teste de Bartlett para verificar a homocedasticidade das variâncias. Uma vez que essa premissa foi atendida, os dados foram submetidos à análise de variância segundo delineamento em blocos casualizados (tratamentos: protocolos P32, P16, P8; bloco: tempo), totalizando em 128 observações por tratamento. As médias foram comparadas pelo Teste de Tukey a $5 \%$ de probabilidade, pelo pacote estatístico STATISTIX 9.0 (2008).

\section{RESULTADOS E DISCUSSÃO}

Houve diferença na RIA para os diferentes protocolos avaliados $(P<0,05$, Tabela 3). O P32 apresentou a RIA próxima de $50 \%$, mostrando que os animais consumiram praticamente a mesma quantidade de ambas as dietas oferecidas, enquanto que 0 P16 apresentou RIA próximo a $55 \%$, indicando que houve maior preferência pela dieta $A$ em relação à $B$. Já o $P 8$ se igualou aos outros protocolos, apesar de ter apresentado RIA mais próxima ao P16.

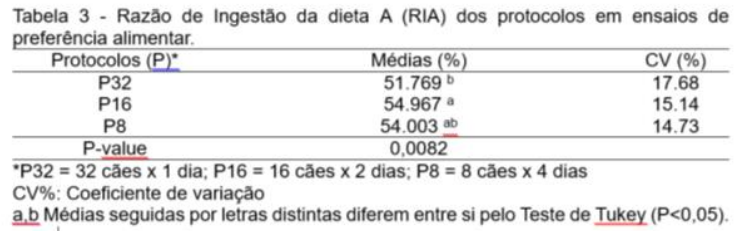

Comportamento neofílico é a definição dada à curiosidade pelo novo (BRADSHAW, 1991), ou seja, é a preferência por um alimento nunca antes experimentado pelo animal ou que não tenha sido recentemente ingerido, permitindo diversificar a dieta e alcançar um melhor equilíbrio nutricional (BOURGEOIS et al., 2006). Tal suposição pode justificar o comportamento dos cães que constituíam o P32, que foram aferidos por apenas um dia, em que a quantidade consumida de ambas as dietas foi próxima.

Por outro lado, com dois dias de avaliação (P16), o momento de curiosidade já havia diminuído, prevalecendo a seleção pela dieta $A$. $O$ P8, em que os animais foram avaliados por quatro dias, se equivaleu aos outros dois protocolos, possivelmente porque 0 tempo em que foram expostos às dietas possibilitou que a curiosidade se diluísse no tempo, mas foi suficiente para que selecionassem uma das dietas como preferida, no caso a dieta $A$.

Para avaliação da primeira escolha entre os protocolos para a dieta $A$ as frequências observadas foram $\mathrm{P} 32=80, \quad \mathrm{P} 16=95$ e $\mathrm{P} 8=74$ (em porcentagem representam, respectivamente, $62,5 \%, \quad 74,22 \%$ e $57,81 \%$ ), não diferindo entre si da FE = 83 (64,84\%) (Gráfico 1). 


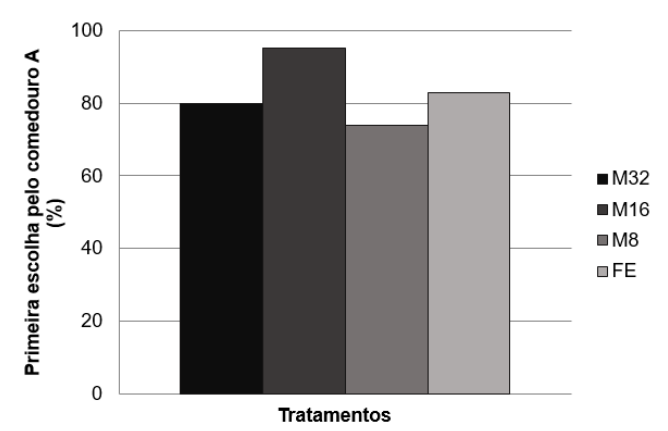

$\mathrm{P} 32=32$ cães $\times 1$ dia; $\mathrm{P} 16=16$ cães $\times 2$ dias; P8 = cães $\times 4$ dias; FE = frequência esperada

Gráfico 1 - Efeito do número de animais e dias de avaliação sobre $1^{\circ}$ escolha em cães.

A partir desses resultados é possível constatar que a adoção de um, dois ou quatro dias de avaliação proporcionam o mesmo resultado final. Isto sugere que, ao contrário da razão de ingestão, a primeira escolha demonstra não sofrer influência do comportamento neofílico. Neste caso, o fator determinante para a escolha entre as dietas foi o palatabilizante utilizado na dieta $A$, que atraiu mais os animais, possivelmente devido a sua maior capacidade de volatilização.

Não foram encontrados outros estudos aferindo dias de avaliação em testes de preferência alimentar. BRITO et al. (2010) avaliaram quatro raças por três dias, precedidos por dois dias de adaptação, e detectaram diferença para primeira escolha entre as dietas analisadas. Da mesma forma, FÉLIX et al. (2012) utilizando quatro raças, avaliadas por dois dias, precedidas de dois dias de adaptação, observaram diferença para primeira escolha entre as dietas A e B. Entretanto, ambos os autores não comentam sobre a adoção ou efeito dos dias sobre os testes de preferência.

Apenas um trabalho foi encontrado avaliando diferentes números de animas, o qual obteve resultados diferentes do presente estudo. Ao comparar testes utilizando 20 e 32 animais, ambos por cinco dias, LAROSE (2003) constatou que os resultados foram significativamente diferentes e a variabilidade na escolha entre as dietas foi menor para o teste que continha 32 animais. $O$ achado é atribuído à quantidade de animais utilizados, justificando que é mais importante a repetibilidade comparado ao número de dias de avaliação, a fim de evitar possíveis vícios de análise. Devido à escassez de pesquisas científicas realizadas no ramo do presente ensaio, são necessários mais estudos a fim de investigar se de fato 0 número de animais a serem utilizados se sobrepõe ao número de dias de avaliação.

\section{CONCLUSÃO}

Por ter apresentado em ambas as avaliações preferência pela mesma dieta (dieta A), o protocolo utilizando 16 cães por dois dias (P16) se mostrou o mais indicado a ser empregado em ensaios de preferência.

\section{REFERENCIAS}

BOURGEOIS, $\quad H . ; \quad$ ELLIOTT, D.; MARNIQUET, $P$. et al. Bases du comportement alimentaire des chiens et des chats. In: Dietary behavior of dogs and cats. Bull. Academie Vétérinaire de France, v.159, n4, p. 31-38, 2006.

BRADSHAW, J.W.S. Sensory and experiential factors in the design of foods for domestic dogs and cats. Proceedings of the Nutrition Society, v.50, p.99-106, 1991.

BRITO, C.B.M.; FÉLIX, A.P.; JESUS, R.M. et al. Digestibility and palatability of dog foods containing different moisture levels, and the inclusion of a mould inhibitor. Animal Feed Science and Technology, v.159, p.150-155, 2010.

FÉLIX, A.P.; CARVALHO, M.P.; ALARÇA, L.G. et al. Effects of the inclusion of carbohydrases and different soybean meals in the diet on palatability, digestibility and faecal characteristics in 
dogs. Animal Feed Science and

Technology, v.174, p.182-189, 2012.

GRIFFIN, R.W.; SCOTT, G.C.; CANTE, C.J. Food Preferences of Dogs Housed in Testing-Kennels and in Consumers' Homes: Some Comparisons. Neuroscience \& Biobehavioral

Reviews, v.8, p. 253-259, 1984.

LAROSE, C. Criteria to assure reliability of palatability tests. In: PETS INTERNATIONAL MAGAZINE. SPECIAL PET FOOD INGREDIENTS \& MACHINERY - SPF. 2003. Proceedings..., 2003. p.1-1.

National Research Council, 2006. Nutrient Requirements of Dogs and Cats. NRC, Natl. Acad. Press,Washington, DC, USA, 2006. 424 p.

PIZZATO, D.A.; DOMINGUES, J.L. Palatabilidade de alimentos para cães. Revista Eletrônica Nutritime, v.5, n.2, p.504-511, 2008.

SOLÀ-ORIOL, D.; ROURA, E.; TORRALLARDONA, D. Feed preference in pigs: effect of cereal sources at different inclusion rates. Journal of Animal Science, v.87, p. 562-570, 2009.

STATISTIX®. Statistix 9 Analytical Software for Windows. Tallahassee, FL, USA. 2008. Disponível em: <http://www.statistix.com/freetrial.html>. Acesso em: 25/12/2012. 